\title{
AC 2010-786: SMART GRID, CLEANTECH, SENSOR NETWORKS COME OF AGE
}

\section{Gary Mullett, Springfield Technical Community College}

Mr. Gary J. Mullett, a Professor of Electronics Technology and Co-Department Chair, presently teaches in the Electronics Group at Springfield Technical Community College in Springfield, MA. A long time faculty member and consultant to local business and industry, Mr. Mullett has provided leadership and initiated numerous curriculum reforms as either the Chair or Co-Department Chair of the four technology degree programs that constitute the Electronics Group. Since the mid-1990s, he has been active in the NSF's ATE and CCLI programs as a knowledge leader in the wireless telecommunications field. A co-founder of the National Center for Telecommunications Technologies (now the ICT Center) located at STCC, Mullett also played a principle role in the development of the innovative and long running Verizon NextStep employee training program. The author of two text books, Basic Telecommunications - The Physical Layer and Wireless Telecommunications Systems and Networks, Mullett did both his undergraduate and graduate work in the ECE Department at the University of Massachusetts at Amherst where he also taught the undergraduate sequence of courses in electromagnetics. He has presented at numerous regional and national conferences and also internationally on telecommunications and wireless topics and on the status of the education of electronics technicians at the two-year college level. His current interests are in the transformation of electronics technician education to incorporate a systems-level approach and applications of the emerging field of networked, wireless sensors. 


\title{
Smart Grid, Cleantech, Sensor Networks Come of Age
}

\begin{abstract}
One of the most active multi-disciplinary research areas in recent years has been that of sensor networks. However, there have been limited numbers of applications that have been deployed on anything other than a test-bed, trial, or custom application basis outside of the automotive industry, which uses this technology extensively, albeit basically limited to within vehicles. These types of networks hold great promise in applications that are geographically widespread but the cost of installation of such networks still tends to be prohibitive. Recently, with a new administration in place, initiatives in clean and renewable energy and efforts to improve the efficiency of our aging infrastructure have rapidly gained traction. Funding from the American Recovery and Reinvestment Act (ARRA) has spawned many initiatives by the power industry to modernize our legacy electrical grid system and transform it into a "smart grid". Furthermore, the use of alternative and renewable energy sources and their interconnections to the national grid are facilitated by an intelligent grid and the use of computerized automation and control systems that utilize remote sensing and communications technologies that are both wireless and wired in nature. The similarities between the upgrading of our telecommunications infrastructure that has occurred over the past fifteen years and is still ongoing today and the plans for the upgrading of the electric grid have many parallels. However, in the case of the smart grid and so called cleantech (i.e. low carbon footprint) initiatives, it is the convergence of several maturing technologies that allows the benefits of these particular applications of sensor network technology to have economic viability when deployed on a large scale. Future sensor network initiatives in transportation applications that will most likely improve fuel efficiency and increase safety (possibly saving many lives and billions of dollars in costs due to fewer accidents) are still waiting for an economic tipping point or similar government stimulus funding before they too will become widespread.
\end{abstract}

\section{Overview}

For the past decade, researchers in many diverse fields have been exploring the possibilities of the use of application specific sensor networks to perform a host of various tasks. This emerging technology paradigm essentially consists of the deployment of an assemblage of complex sensors with embedded (ambient) intelligence and advanced actuators. Combining this distributed ambient intelligence with modern data-transport and networking technologies and applicationenabling software gives rise to new and potentially quality-of-life changing applications and in many already existing situations, the ability to increase system efficiency. Unfortunately, the high cost of deployment of such systems, especially if they are geographically dispersed, and the lack of appropriate standards involving various aspects of these systems has, to this time, prevented the widespread deployment and adoption of such systems. The automotive industry and its extensive use of sensor networks within vehicles is a notable exception to the implementation of this new and promising technology. However, in the automotive industries' case, the economic barrier of geographically large networks does not come into play and, to a great extent, emissions and fuel efficiency regulations have been the driving force behind the adoption of this technology. 
As the 2010 decade commences, several factors have combined to give this technology a boost. With advances in wireless mesh technologies and the continued deployment of fixed and wireless broadband systems by major telecommunications service providers, society is another step closer to ubiquitous high-speed Internet access and the self-organizing wireless ad-hoc networks that are necessary for mobility and the deployment of geographically widespread sensor networks. Recently, with a new administration in place, initiatives in clean and renewable energy and efforts to improve the efficiency of our aging infrastructure have rapidly gained traction on both a federal and state level. Under the 2009 American Recovery and Reinvestment Act (ARRA), funding through the Department of Energy (DOE) for $\$ 36.7$ billion dollars has been allocated to various energy related initiatives ${ }^{1}$. Figure 1 , shown here, gives a further breakdown of the general areas to be funded.

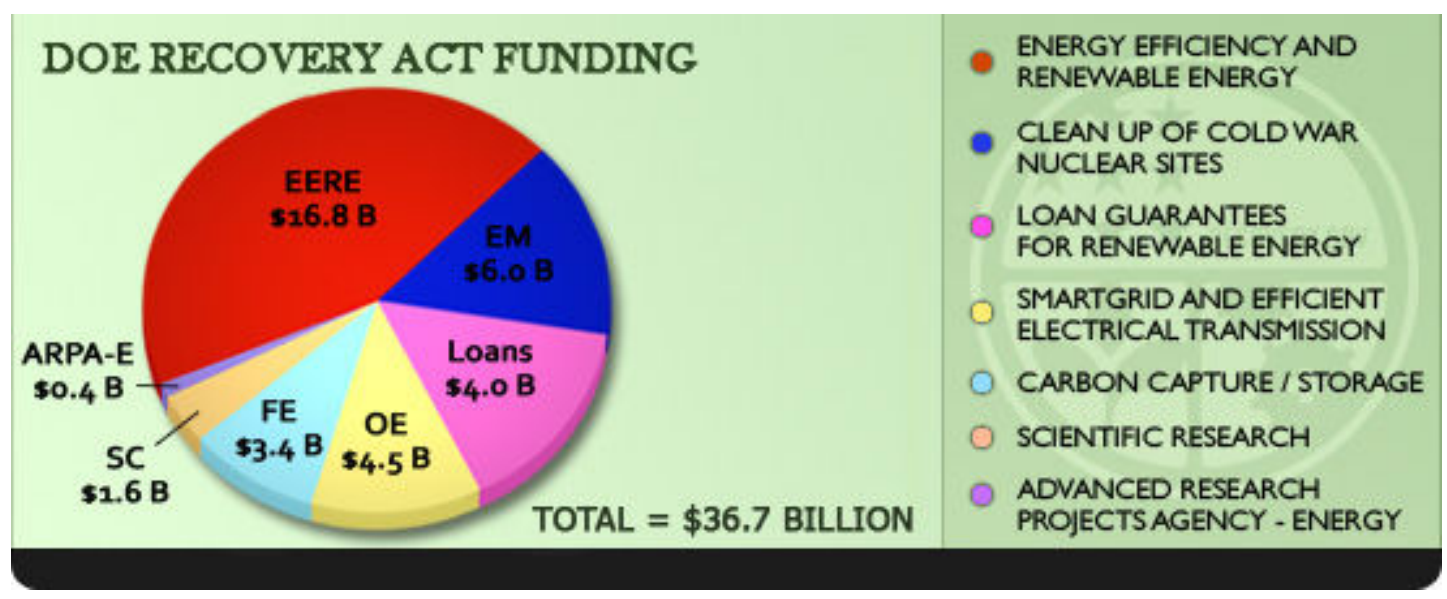

Figure 1 - Breakdown of DOE funding from the ARRA Act (Source DOE)

Through the Office of Energy Efficiency and Renewable Energy (EERE) there is funding for $\$ 16.8$ billion dollars for various energy efficiency and renewable energy projects. As mentioned earlier, sensor networks are an enabling technology for many applications that can increase energy efficiency. The Office of Electricity Delivery \& Energy Reliability (OE) has $\$ 4.5$ billion dollars for Smart Grid and efficient energy transmission projects. Sensor network technology is the enabling technology for the Smart Grid. The DOE has already called for proposals from the electrical power distribution industry to begin the long needed up-grade of the aging electrical grid infrastructure in the United States. Recently, matching funds in the amount of $\$ 3.4$ billion dollars were awarded to approximately 100 Smart Grid Investment Grant applicants by $\mathrm{OE}^{2}$. Some in this industry have termed this the biggest event to impact the power industry in the last hundred years during which time the generation, delivery, and consumption of electricity has remained fundamentally unchanged. Much of the funding is going to support projects that will affect three basic areas of power distribution: deployment of smart meters and energy management displays, automated substations and smart transformers, and 850 additional synchrophasors that will allow the United States to employ a wide-area-monitoring system (WAMS) for the entire national grid $^{3}$. Furthermore, as the grid is transformed, the increased use of alternative and renewable energy sources and their interconnection to the national grid will be facilitated by the use of computerized automation and control systems that utilize remote sensing 
and communications technologies that are both wireless and wired in nature. Recently, predictions for global spending on Smart Grid technologies of 200 billion dollars by 2015 have been made ${ }^{4}$ with just as optimistic predictions (typically, by politicians) of the resulting job growth that will occur in this sector.

The similarities between the upgrading of our communications infrastructure that has occurred over the past fifteen years (and is still ongoing today) and the plans for the upgrading of the electric grid have many parallels. Interestingly, the Smart Grid needs to allow the flow of energy through the grid in both directions to achieve the vision that many have of its ultimate operation. This long-term goal is very reminiscent of the recent transition of this country's cable TV systems from a one-way, broadcast, delivery system to a two-way telecommunications network. Obviously, there needs to be job training and other educational initiatives to provide the future Smart Grid workforce and, just as important, customer education needed to deal with the Smart Grid and the energy management potentials it offers to the end-user, the energy consumer. DOE has recently requested proposals for such initiatives and will be releasing funding for short-term projects and programs early in 2010. How post-secondary two- and four-year educational institutions with legacy technology and engineering programs will need to respond to the longerterm educational needs required by this emerging technology and the resulting spin-off applications will be addressed later in this paper.

\section{Smart Grid and Microgrid Technologies}

Just what is the Smart Grid? There are many levels of deployment to the Smart Grid and at this time no single definitive architecture. In theory, a Smart Grid is really a service platform that will help to reduce energy consumption and greenhouse gas emissions. This service platform will drive optimization, improve utilization and efficiencies, and enhance the reliability of the nation's transmission and distribution infrastructure. Furthermore, it will allow for the interfacing of green, cleantech, and storage (i.e. various alternative energy) sources to the grid. At the simplest level, on the consumer side (known as customer facing functions), a Smart electric meter can be installed that allows for the simple disconnection of service at the meter, controlled by a signal from the distribution system or power supplier. At a much higher level, a Smart meter with communication links to the customer and various energy consuming devices in the residence, in conjunction with energy management software tools, can allow the consumer to control their energy usage and ultimately their costs. In between, or in conjunction with the last case, is the scenario where the electric power supplier remotely controls thermostat and energy consuming devices in the residence. Other Smart Grid functions that deal with the distribution system and alternative energy sources and/or energy storage systems are termed "distribution grid-facing functions" by the power industry. Included in this class of functions is the remote monitoring and control of the distribution grid and anything connected or interfaced to it. At the present time, we are only at the infancy of the Smart Grid and it will take some time (years) before experience with the system will be translated into turn-key applications. However, the potential to provide energy savings is real and significant. Some have predicted that once installed, this technology could save $10-15 \%$ of the energy presently being used in this country.

How is the Smart Grid implemented? To implement the Smart Grid requires that a two-way communications system is overlaid on the electric grid. This network must have the speed and capacity to enable advanced metering, home energy automation and management, distribution 
automation and management, and distributed generation and energy storage. Furthermore, home area networking (HAN) and automation technology (other emerging technology areas) are needed to enable the consumer facing applications and SCADA (supervisory control and data acquisition) is typically needed for distribution grid-facing applications such as the integration of alternative energy sources or energy storage technologies onto the grid ${ }^{5}$. Most of the technology required to build the Smart Grid already exists. However, as of this time, industry experts will admit that some of the components needed to implement the vision of the Smart Grid do not exist! Smart appliances are predicted to begin production sometime this year (2010) and be on the market before the end of the year. Furthermore, standardization of various aspects of the Smart Grid have been slow to be adopted - the interface to appliances being a case in point. The National Institute of Standards and Technology (NIST) has been given primary responsibility for the Smart Grid Interoperability Standards Project which involves coordinating development of a framework that includes protocols and model standards for information management to achieve interoperability of smart grid devices and systems ${ }^{6}$. A typical Smart Grid architecture with all its envisioned parts is shown here as Figure 2.

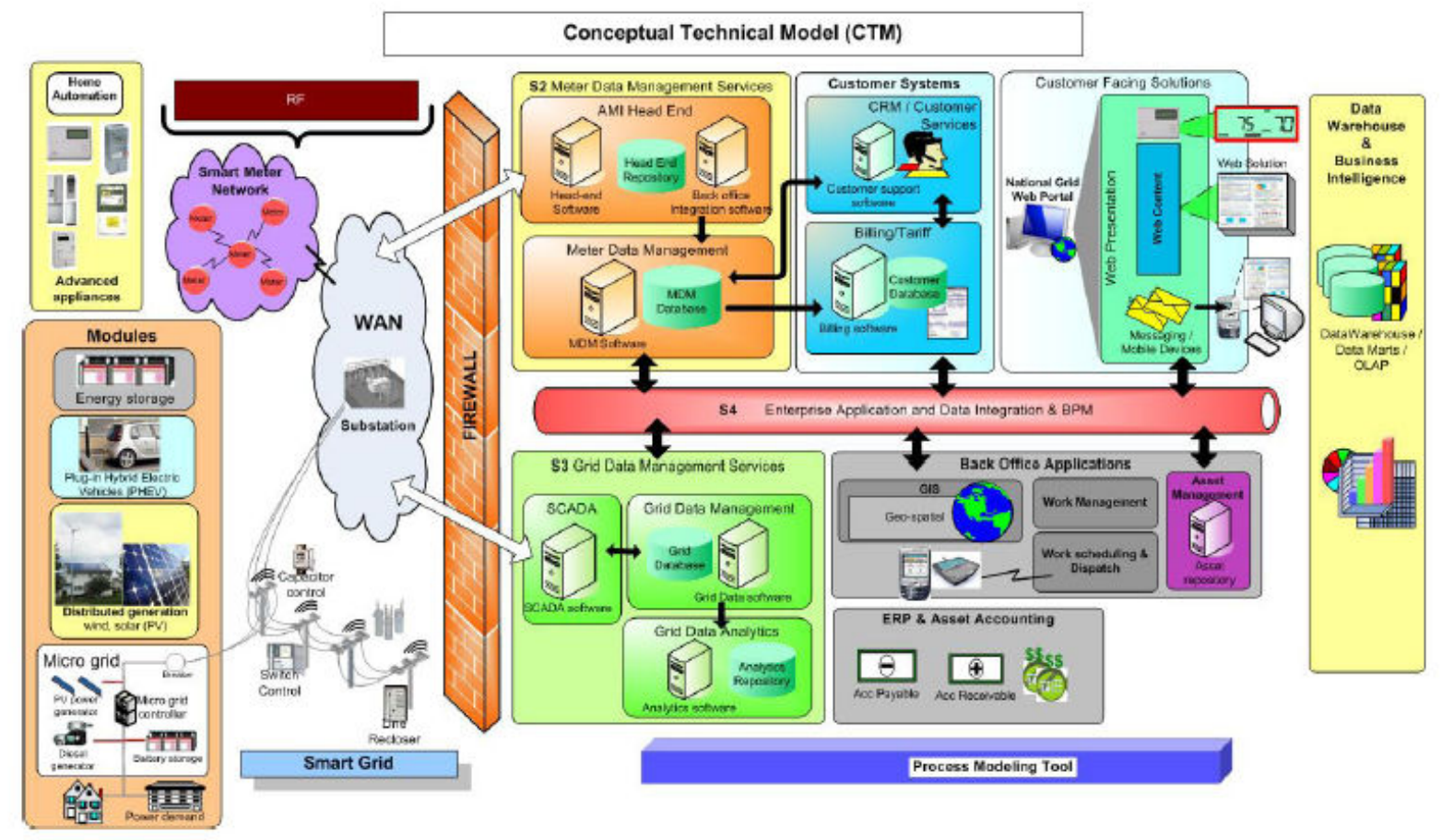

Figure 2 - Conceptual technical model of the Smart Grid (Source National Grid - Proposal submitted to Rhode Island Public Utilities Commission - Smart Grid Pilot Program ${ }^{7}$ )

As can be seen from this diagram, a full blown implementation of the Smart Grid brings a great deal of electronics and computer technology (both hardware and software) into the picture. From various networking technologies (e. g. WAN, LAN, home area networks [HAN], building area networks [BAN], industrial area networks [IAN], field area networks [FAN], neighborhood area networks [NAN], and industry specific networks such as SCADA), to different technology implementations of these networks (Wi-Max, Wi-Fi, ZigBee, Cellular, BPL [broadband over power line], Ethernet [i.e. wireline], and fiber optic technology), to control electronics at the physical layer (home automation), and finally to data management applications, it is no wonder 
that corporate heavy weights like Cisco (networking), Honeywell (controls), Intel (embedded processors), and Microsoft (software) have taken such an interest in the Smart Grid.

Up to this point, no mention has been made of "microgrids" or how industrial power users will be impacted by the Smart Grid. Certainly, large industrial complexes and office buildings consume tremendous amounts of electrical power and therefore have the potential to be made more efficient through modern control and automation techniques. Furthermore, there are many initiatives for what is known as "sustainability" in the building automation field for both new buildings and up-grades of older structures by adding alternative energy and/or cleantech sources to the power supply mix. One might note the reference to "Micro grid" in Figure 2 (note the bottom left-hand corner). Microgrids are typically considered to be "self-contained" Enterprises that might have one to several alternative energy sources on-site. These alternative energy sources are tied into the electrical power system of the Enterprise but the Enterprise electrical network or "microgrid" has a single source of connection (similar to a network gateway) to the distribution power grid that can be controlled by the Smart Grid. Note that the Enterprise is not limited in size and therefore could be a small business (single building), or a large office building, an entire college campus, or a large industrial complex, or even a small community or city with a very large total energy usage. With this single point of connection, a Smart Grid enabled distribution system has the ability to monitor the Enterprise's microgrid. As a direct consequence, the distributed electrical generator or generators that are owned by the Enterprise and tied to the Enterprise electrical system can go on- or off-line as conditions vary without causing a disturbance to the power distribution grid. Many feel that as more alternative energy sources become available and deployed, Enterprise microgrids will proliferate. The vision of numerous distributed alternative energy sources and energy storage facilities tied to the distribution grid does not happen without the functionality provided by the Smart Grid to control the flow of energy and mitigate load distribution instabilities. Furthermore, the future of electric vehicles (EVs) is tightly coupled to the re-engineering of the electrical grid so that it is capable of supporting the demand for energy that will be generated by this new technology on a twentyfour hour basis, not just during off-peak hours.

\section{Educational Initiatives}

An interesting question is where will the workers come from to implement the technology of the Smart Grid and maintain it once it has been installed? As already mentioned, DOE has requested grant proposals for Smart Grid training and education initiatives. However, these are short-term programs with a fairly specific and short-range focus. Recently, many colleges have instituted new programs in "green" and "sustainability" technology. The Association for the Advancement of Sustainability in Higher Education (AASHE) lists various college programs at different completion levels (i.e. bachelors, masters, and $\mathrm{PhD})^{8}$. However, if one takes a quick look at the programs, one does not see much of a correlation between the skill sets needed for Smart Grid technology and the typical curriculum of these programs (the majority of which tend to lean towards environmental areas). Instead, it appears that the power industry is reinvesting in power engineering programs with the ultimate goal to develop a workforce capable of handling the design aspects needed for Smart Grid implementation and research into innovative distribution grid control strategies. But what about the hardware and networking aspects of the Smart Grid? It is this author's contention that the physical layer (borrowing the term used by the OSI model for networking) of the Smart Grid is best serviced and maintained by someone from the two-year 
associate in science (AS) degree level with an electrical/electronics/instrumentation/networking background. Of course, this "Smart Grid technician" will need training on topics that may or may not be in their present program of study and most likely would not have been in a program of study if they have not recently been in school.

It would appear that there is a need for the two- and four-year colleges to begin the process of creating options or certificate programs that will meet the workforce needed to deal with the emerging technology that is enabling the Smart grid and the applications enabled by the implementation of this intelligent power delivery infrastructure. It would further appear that these programs should be based in electrical and electronics fundamentals but would need course components covering the fields of electrical power distribution, modern instrumentation and control, sensors, communications, and networking technology. Hopefully, industry will partner with educational institutions to provide direction to these efforts and hopefully this will happen sooner than later. To date, the National Science Foundation (NSF) has funded a small Course, Curriculum, and Laboratory Improvement (CCLI) project titled "Sensor Network Education Project" that has produced some generic curriculum and laboratory experiments in the sensor networks area at the two-year college level. This project utilizes a specially configured sensor network test-bed dubbed "SensorNet" that interfaces networked embedded controllers to form various simple sensor networks but much more curriculum development needs to be done in this area before entire programs will be able to be put in place. Some Electronics Engineering Technology programs ${ }^{10}$ have introduced courses in Home Networking and basic Sensor Network technology but this is not commonplace throughout this discipline. Furthermore, it appears fairly obvious that any approach to create new curriculum in this area needs to embrace the idea that this emerging technology space brings together several different technology disciplines that will require a blending process to provide the desired final curriculum.

Some might argue that the networking component of the Smart Grid will best be handled by the IT staff of the particular organization or Enterprise at the microgrid level or by the IT staff of power distribution companies. However, this would be a naïve view of just what these systems entail. Most physical applications of sensor networks use non-Enterprise, industry/function specific, area networks. Today, from the control and automation field there are several standardized "fieldbus" implementations (both wired and wireless). From the building automation field there are the popular LonWorks and BACnet technologies. Most utility industry proposals for smart grid implementation discuss the use of Wi-Max, ZigBee, wireless mesh, power-line, and home area networking technologies (as well as, the other lesser known area networks introduced previously) for applications of consumer or supplier initiated energy control. Although, Enterprise data networks can and will be involved in these applications, at this point, most of that involvement will be at a higher supervisory level, not at the control level which tends to be machine-to-machine (M2M) interaction. Furthermore, wide area networks to service the relatively large geographic foot-print of the Smart Grid tend to be the domain of the telecommunications service industry. It is worth repeating that the physical layer of the sevenlayer OSI-ISO model is not typically the domain of the information technology (IT) professional especially when it involves esoteric, industry specific networking technologies and ambient intelligence in the form of modern programmable embedded electronic hardware coupled with sophisticated sensors and actuators. This area of technology (electronics hardware) is just not addressed in the typical IT curriculum. 


\section{The Future}

In this author's view, the Smart Grid is but the first of many large initiatives involving sensor networks that will be implemented in the coming years. Building and home automation have already been mentioned as technologies that, coupled with sensor networks, could most certainly provide increased energy efficiency and increased safety and security. Similarly, "infrastructure health" type of sensor networks (applications based in the civil engineering field) could increase public safety and improve physical infrastructure lifespan by warning of needed maintenance and/or potentially catastrophic conditions (e.g. failing bridges, toxic spills, etc). On the medical front, in-home health care monitoring (known as e-Healthcare) for an aging population is on the radar screen of many researchers and the health care industry ${ }^{11}$. Recent automobile recalls have raised the public's awareness of the use of "automonics" (i.e. automobile - electronics) controls. Present day statistics indicate that $37 \%$ of a new automobile's cost is attributable to the vehicle's electronics hardware and the software that controls it. This figure will most likely increase as time goes on and new safety features are added to vehicles that will allow them to be able to communicate with each other (known as vehicle-to-vehicle or V2V) through ad-hoc networks and with roadside information portals (vehicle-to-roadside or V2R). All of this predicted, as we move towards the deployment of an Intelligent Transportation System (ITS) for the nation's highways ${ }^{12}$ using ad-hoc wireless sensor network technology. The next Smart Grid could be the nation's interstate highway system! The possible applications and potential benefits of sensor based networks are mind-boggling!

\section{Conclusions}

The Smart Grid will soon be a reality. Our post-secondary educational institutions need to start their development of new programs or certifications that deal with this emerging technology or the modification of existing programs to meet the need for qualified individuals to support this new area and to also educate the end users of systems that employ it. The skill sets needed will be interdisciplinary by today's curriculum standards and certainly should be system centric and not device centric in this era of system-on-a-chip (SoC) electronics technology. Faculty from the various legacy technology areas previously mentioned will need to work together to achieve common goals in workforce development. An education summit of government, industry, and academia stakeholders would be a good starting point in the development of any new curricula and certifications. The National Science Foundation's Advanced Technological Education (ATE) program and the Department of Energy (DOE) have recently started to jointly request proposals in this area. This type of funding will be necessary to allow the collaborations and industry and academia interaction that is required to determine the best direction forward.

It has been said that the last century was the century of the invention of electronics devices. This century will focus on the creation of intelligent systems (enabled by electronic devices and other new technologies like nanotechnology, micro-electro-mechanical systems [MEMS], photonics, biophotonics, etc) that will be further facilitated by a ubiquitous Internet to create a type of "sensing skin" within our environment to potentially improve every aspect of human endeavor. The academic community, with ongoing input from the affected industries and other involved parties, needs to be ready to provide the education that will be required by the technicians, technologists, and engineers that will deal with these emerging networked sensor systems that will eventually add intelligence to our infrastructure. 
References:

1. DOE website: www.energy.gov/recovery/index.htm

2. DOE Office of Electricity Delivery \& Energy Reliability $(O E)$ website: www.oe.energy.gov/recovery/1249.htm

3. Will We Get Our Money's Worth? \$3.4 Billion in Smart Grid Stimulus Grants Go to 100 Projects, October 27, 2009, Staff Report, Smart Grid NEWS.COM,

www.smartgridnews.com/artmen/publish/Stimulus_News_Digest_News

4. Global Spending of Smart Grid Technologies to hit $\$ 200$ billion by 2015, December 28, 2009, Staff Report, Smart Grid NEWS.COM, www.smartgridnews.com/artmen/publish/

5. National Grid website: www.nationalgridus.com/non_html/SmartGrid_filing_summary.pdf

6. NIST website: www.nist.gov/smartgrid/

7. Same as 5

8. AASHE website: www.aashe.org

9. A Novel Interdisciplinary Sensor Networks Laboratory, by Gary J. Mullett, Proceedings of the 2009 American Society of Engineering Educators Annual Conference and Exposition, Austin, TX

10. www.stcc.edu/academics/electsysengtech.asp

11. Wireless Technologies for e-Healthcare, IEEE Communications Magazine, Vol.17 No. 1, February, 2010

12. Department of Transportation website: www.its.dot.gov/resources.htm 